\title{
Prevalence of Essential Tremor in a Multiethnic, Community-Based Study in Northern Manhattan, New York, N.Y.
}

\author{
Elan D. Louis ${ }^{\text {a-d }}$ Sujata P. Thawani ${ }^{d}$ Howard F. Andrews ${ }^{a, c, ~ e ~}$ \\ ${ }^{a}$ G.H. Sergievsky Center, ${ }^{b}$ Department of Neurology and 'Taub Institute for Research on Alzheimer's Disease \\ and the Aging Brain, College of Physicians and Surgeons, and Departments of ${ }^{\mathrm{d}}$ Epidemiology and ${ }^{\mathrm{e} B i o s t a t i s t i c s,}$ \\ Mailman School of Public Health, Columbia University, New York, N.Y., USA
}

\section{Key Words}

Essential tremor • Epidemiology $\cdot$ Prevalence $\cdot$ Ethnicity $\cdot$ Clinical

\begin{abstract}
Background: Our aims were to: (1) estimate the prevalence of essential tremor (ET) in a community-based study in northern Manhattan, New York, N.Y., USA; (2) compare prevalence across ethnic groups, and (3) provide prevalence estimates for the oldest old. Methods: This study did not rely on a screening questionnaire. Rather, as part of an in-person neurological evaluation, each participant produced several handwriting samples, from which ET diagnoses were assigned. Results: There were 1,965 participants (76.7 \pm 6.9 years, range $=66-102$ years); 108 had ET [5.5\%, 95\% confidence interval $(\mathrm{Cl})=4.5-6.5 \%]$. Odds of ET were robustly associated with Hispanic ethnicity versus white ethnicity [odds ratio $(O R)=2.19,95 \% \mathrm{Cl}=1.03-4.64, \mathrm{p}=0.04]$ and age $(\mathrm{OR}=$ $1.14,95 \% \mathrm{Cl}=1.03-1.26, \mathrm{p}=0.01)$, i.e. with every 1 year advance in age, the odds of ET increased by $14 \%$. Prevalence reached $21.7 \%$ among the oldest old (age $\geq 95$ years). Conclusions: This study reports a significant ethnic difference in the prevalence of ET. The prevalence of ET was high overall (5.5\%) and rose markedly with age so that in the oldest old, more than 1 in 5 individuals had this disease.
\end{abstract}

Copyright $\odot 2009$ S. Karger AG, Basel

\section{KARGER}

Fax +41613061234 E-Mail karger@karger.ch www.karger.com
(ㄷ) 2009 S. Karger AG, Basel

\section{Introduction}

Essential tremor (ET), a progressive neurological disease, is regarded as one of the most prevalent neurological disorders [1-4]. Yet there are wide disparities in prevalence estimates, with an approximately 3,000-fold difference between the lowest and highest estimates [5], so that prevalence has not been established with precision. A major methodological problem is that, with few exceptions $[1,6,7]$, the more than 20 prevalence studies have relied on screening questionnaires, which generally have low sensitivity.

Age is a well-established risk factor for ET $[8,9]$, yet little is known about other key disease determinants. For example, there are few direct comparisons between persons of different ethnicity [10-12], so that the role of ethnicity as a disease determinant has not been examined in detail. Even with regard to age, with a rare exception [6], studies have not reported data on prevalence among persons aged 90 and older, so that it is not clear whether prevalence continues to rise or declines towards the end of the age spectrum.

We assessed the prevalence of ET in a large community-based health survey of persons 65 years and older (range $=65-102$ years) living in northern Manhattan, New York, N.Y., USA. We assessed participants indepen-

Dr. Elan Louis

Unit 198, Neurological Institute

710 West 168th Street

New York, NY, 10032 (USA)

Tel. +1 212305 9194, Fax +1 212305 1304,E-Mail EDL2@columbia.edu 
dent of screening results in order to obtain a more complete estimate of ET prevalence. The multiethnic nature of this sample further allowed direct comparisons of ET prevalence across these ethnic groups.

\section{Methods}

\section{Study Sample}

2,776 individuals participated in a prospective study of aging and dementia in Medicare-eligible northern Manhattan residents, age $\geq 65$ years (Washington/Hamilton Heights-Inwood Columbia Aging Project, WHICAP II). The WHICAP II cohort represents a combination of continuing members of a cohort originally recruited in 1992 (WHICAP I; $n=602$ ) and members of a new cohort recruited between 1999 and $2001(n=2,174)$. The sampling strategies have been described in detail [13]. Prevalence was previously estimated in a larger sample of members recruited in 1992 [10]; therefore, the current analyses were restricted to the baseline assessment of the new cohort recruited between 1999 and 2001 ( $\mathrm{n}=2,174)$. Informed consent and study procedures were approved by the Columbia University Institutional Review Board.

\section{In Person Evaluation}

A trained research assistant collected demographic information (including self-reported race, which was coded as non-Hispanic white, Hispanic, non-Hispanic African-American, and other) and administered a structured interview of health, which included questions on current and past medical conditions and current medication use. The structured interview also included the questions 'do your arms or legs shake?', 'have you ever been told that you have Parkinson's disease?', and 'have you ever taken levodopa or Sinemet?' Names and dosages of all current medications were collected.

Each participant also underwent a standardized neurological examination by a general physician. The physician was not asked to comment on or rate action tremor but performed an abbreviated (10-item) version of the motor portion of the Unified Parkinson's Disease Rating Scale (UPDRS) [14], and assigned a preliminary diagnosis of Parkinson's disease (PD) based on the presence of 2 or more cardinal signs. Using the same criteria, PD diagnoses were then confirmed by a study neurologist based on a second, more detailed neurological examination.

As noted above, examining physicians were not asked to rate action tremor. Hence, ET diagnoses were assigned at a later point based on handwriting samples. As part of his or her evaluation, each participant was asked to generate 2 handwriting samples. The first set of handwriting samples was administered as part of a neuropsychological test battery. It was comprised of a series of 5 standard shapes (a triangle, a diamond, a triangle overlapping a square, a series of lines at different angles, and a cube) that had to be copied [15], and a trail-making test in which the participant was asked to draw a series of lines connecting numbered circles [16]. A second handwriting sample was collected as part of a literacy test (10-60 min after the first sample); the participant was asked to copy a standardized handwritten sentence, 'I have a calendar in my room' onto a sheet of paper.

Prevalence of ET in a Multi-Ethnic Community
Rating Handwriting Samples

A medical student (S.T.) was trained by a senior neurologist specializing in tremor disorders (E.D.L.) to rate the severity of tremor in the 5 shapes and the trail-making test. Tremor was rated from 0 to 2 in each of the 6 items. The ratings were: 0 (no tremor), 0.5 (possible tremor), 1.0 (clear tremor that was mild, equivalent to a rating of 2 on an Archimedes spiral in the rating scale of Bain and Findley [17]), 1.5 (mild to moderate tremor, equivalent to a rating of 3-4 in Bain and Findley [17]), 2 (moderate or greater tremor, equivalent to a rating $\geq 5$ in Bain and Findley [17]) (fig. 1). Based on the six rated items, a total tremor score was generated for each participant (range $=0-12$ ). After training was completed, agreement between the medical student and senior neurologist was assessed using handwriting samples from 25 participants, and agreement was substantial (for total tremor score, intraclass correlation coefficient $=0.80$ ). The student then began to review the research records of each participant, rating tremor. During the course of these ratings, which required 3 months, every 40 th sample (i.e. $2.5 \%$ of all samples) was selected for independent rating by the student and the senior neurologist to ensure that agreement remained high. For these ratings, the intraclass correlation coefficient $=0.71$.

\section{ET Diagnosis}

Bain and Findley [17] suggested that their tremor rating $\geq 2$ be used to distinguish ET from enhanced physiological tremor because this rating corresponded with twice that of the 95th percentile seen in healthy controls. As noted above, their rating of 2 is the visual equivalent to our rating of 1.0. A tremor rating of 1.0 on each of our six rated items would result in a total tremor score of 6.0. To be more inclusive (i.e. accounting for the possibility that 1 of the 6 items could have received a rating of 0.5 ), we considered those with a total tremor score of 5.5 or higher as having a preliminary diagnosis of ET and these participants were selected for further consideration. The senior neurologist reviewed their records, rerating tremor and assigning a total tremor score. As an additional test, the handwritten sentence was rated by the senior neurologist using the published guidelines of Bain and Findley [17], with any Bain and Findley rating $\geq 2$ being considered consistent with ET. A final diagnosis of ET was assigned when the senior neurologist confirmed a total tremor score of 5.5 or higher or rated the handwritten sentence $\geq 2$ (fig. 2). Participants were not assigned a final diagnosis of ET if they were diagnosed with $\mathrm{PD}$, were ever told they had PD, had used levodopa at any point in their lives, or if the tremor was related to another neurological disorder. Subsequently, 9 of the ET cases were randomly selected for enrollment in an epidemiological study of ET [18] and each had a complete videotaped tremor examination (sustained arm extension, pouring, drinking, using a spoon, finger-nose-finger maneuver and writing); the diagnosis of ET was confirmed in $100 \%$ of these based on published research criteria (moderate or greater amplitude tremor during 3 activities or a head tremor in the absence of PD, dystonia or another neurological disorder) [18].

\section{Final Sample}

Complete data were available on 1,965 (90.4\%) of 2,174 participants. The remaining 209 participants refused the writing tasks due to poor eye sight or difficulty following the instructions. In one instance, a participant completed the drawings but not the 
A

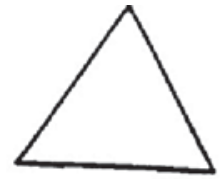

B

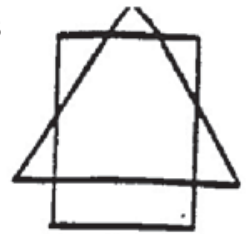

D

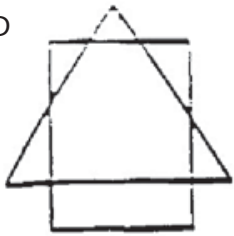

F

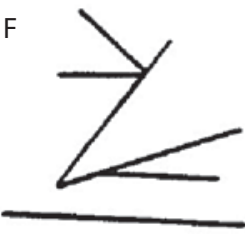

G

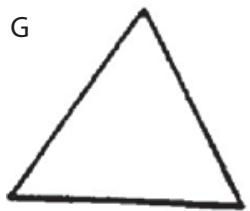

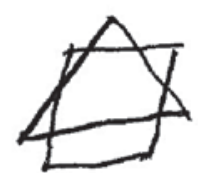

$\backslash$
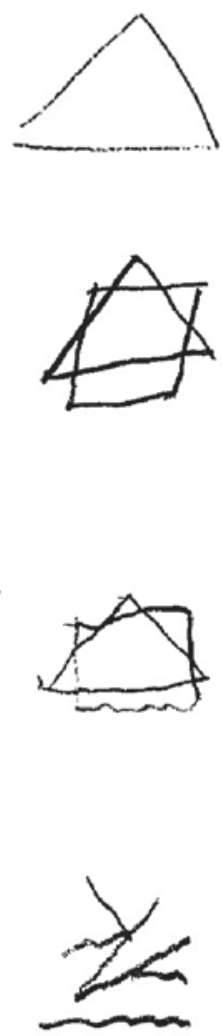

E
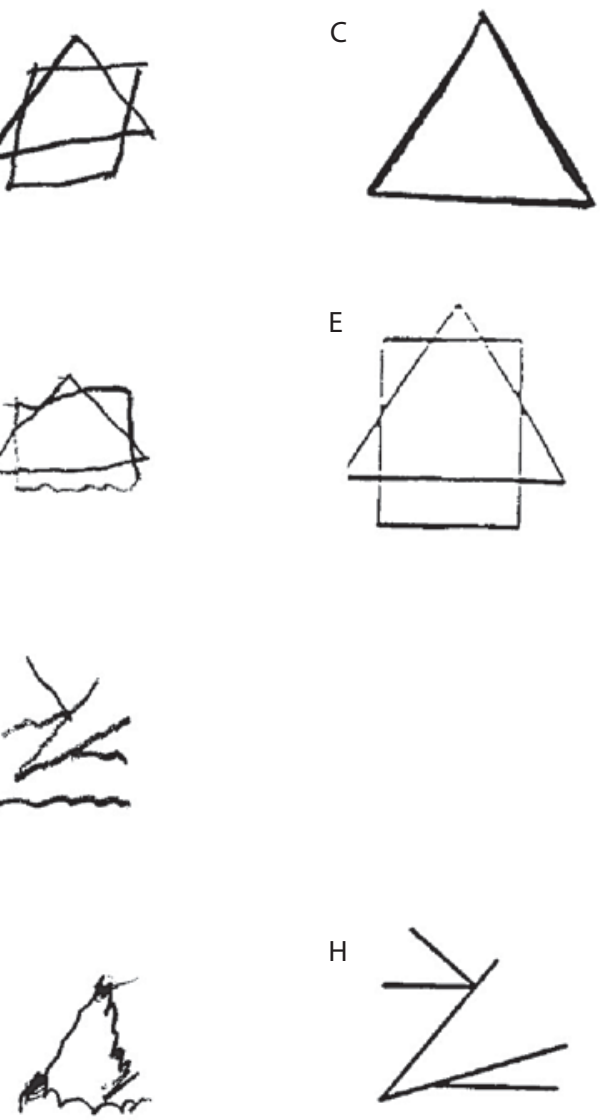

$\mathrm{H}$

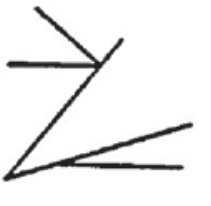

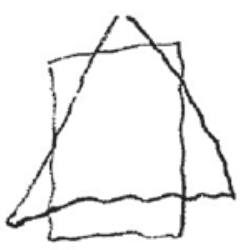
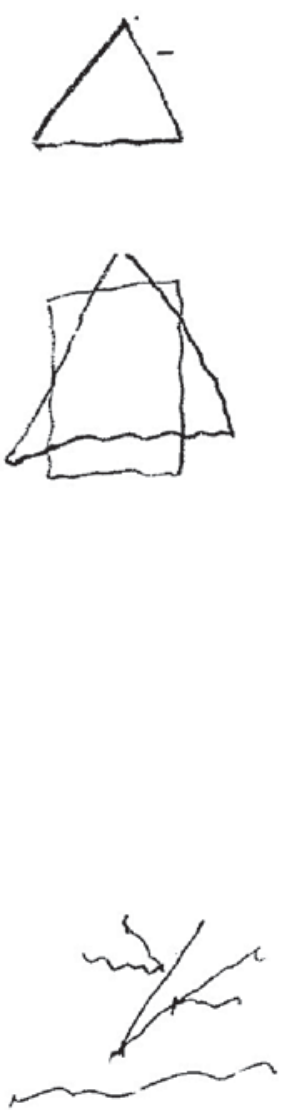

Fig. 1. Examples of drawings with tremor ratings of $0(A), 0.5(B, C), 1.0(D, E), 1.5(F)$, and 2 (G, H). For each example (A-H), the preprinted sample is on the left and hand-drawn copy by the study participant is on the right.

Fig. 2. Example of handwritten sentences with ratings of 0 (A) and 2 (B).

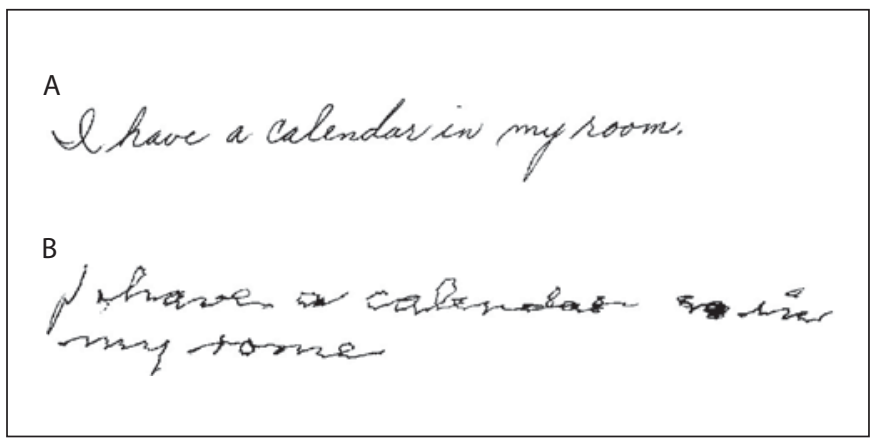


written sentence; this was because tremor made writing difficult.

Statistical Analyses

$\chi^{2}$ tests were used to compare proportions. We calculated point estimates and 95\% confidence intervals (95\% CIs). Overall frequency was provided as a crude estimate and adjusted estimates (2000 United States Census, age $\geq 65$ ) [19].

\section{Results}

The mean \pm SD age of the final sample of 1,965 participants was $76.7 \pm 6.9$ years (range $=66-102) ; 1,306$ (66.5\%) were women. Ethnicity was 589 (30.0\%) nonHispanic white, 642 (32.7\%) non-Hispanic AfricanAmerican, 702 (35.7\%) Hispanic, and 32 (1.6\%) other. Mean education was $10.4 \pm 4.8$ years. Forty $(2.1 \%)$ of 1,965 were diagnosed with PD or had previously been told they had PD or had used levodopa at any point in their lives.

One-hundred-forty-two (7.2\%) of 1,965 participants were assigned a preliminary diagnosis of ET, but 13 were excluded because they were diagnosed with PD or had been told they had PD or had used levodopa at any point in their lives, leaving $129(6.6 \%$ of 1,965$)$ participants with a preliminary diagnosis of ET. A final diagnosis of ET was assigned to 108 of 1,965 participants (crude prevalence $=$ $5.5 \%, 95 \% \mathrm{CI}=4.5-6.5 \%)$. After age adjustment to the 2000 United States Census, the estimated prevalence in the United States population (age $\geq 65$ years) was $5.0 \%$, $95 \% \mathrm{CI}=4.0-6.0 \%$, and after similar adjustment for Hispanic status, prevalence was $4.9 \%, 95 \% \mathrm{CI}=4.0-5.9 \%$. Thirty-four (31.5\%) of 108 had answered 'yes' to the question 'do your arms or legs shake?'

The prevalence of ET was similar by gender. It was higher in African-Americans and Hispanics than whites and increased with age, reaching $21.7 \%$ among the oldest old (age $\geq 95$ years) (table 1 ). The prevalence of ET is shown within strata defined by ethnicity and age (table 2).

In a logistic regression analysis that included age, gender and ethnicity, the odds of ET (dependent variable) were associated with age [odds ratio $(\mathrm{OR})=1.14$, $95 \% \mathrm{CI}=1.03-1.26, \mathrm{p}=0.01$, i.e. with every 1 year advance in age, the odds of ET increased by 14\%) and Hispanic versus white ethnicity $(\mathrm{OR}=2.19,95 \% \mathrm{CI}=$ 1.03-4.64, $\mathrm{p}=0.04)$ but not with female gender $(\mathrm{OR}=$ $1.07,95 \% \mathrm{CI}=0.58-1.96, \mathrm{p}=0.83)$ or African American versus white ethnicity $(\mathrm{OR}=1.50,95 \% \mathrm{CI}=0.66-3.37$, $\mathrm{p}=0.33)$.

Table 1. Prevalence of ET by gender, ethnicity and age stratum

\begin{tabular}{lll}
\hline & $\begin{array}{l}\text { ET cases/ } \\
\text { participants, } \mathrm{n}\end{array}$ & $\begin{array}{l}\text { Crude } \\
\text { prevalence, } \%\end{array}$ \\
\hline $\begin{array}{ll}\text { Gender } \\
\text { Men }\end{array}$ & $38 / 659$ & $5.8(3.9-7.5)$ \\
Women & $70 / 1,306$ & $5.4(4.1-6.5)$ \\
Ethnicity & & \\
$\quad$ Non-Hispanic white & $18 / 589$ & $3.1(1.6-4.4)$ \\
Non-Hispanic & & \\
$\quad$ African-American & $38 / 642$ & $5.9(4.1-7.7)$ \\
Hispanic & $51 / 702$ & $7.3(5.3-9.1)$ \\
Other & $1 / 32$ & $3.1(0.0-8.1)$ \\
Age (10-year strata) & & $2.5(1.5-3.5)$ \\
65-74 & $22 / 868$ & $6.8(5.0-8.4)$ \\
$75-84$ & $55 / 812$ & $9.9(6.3-13.5)$ \\
85-94 & $26 / 262$ & $21.7(4.4-37.7)$ \\
95 and older & $5 / 23$ &
\end{tabular}

$95 \% \mathrm{CI}$ is shown in parentheses. For gender, $\chi^{2}=0.14, \mathrm{p}=0.71$. For ethnicity, $\chi^{2}=11.55, p=0.009$. (For white vs. African-American, $\chi^{2}=5.80, p=0.016$; for white vs. Hispanic, $\chi^{2}=11.22, p=$ 0.001; for Hispanic vs. African-American, $\chi^{2}=0.98, p=0.32$ ). For age (10-year strata), $\chi^{2}=38.78, \mathrm{p}<0.001$.

Table 2. Prevalence of ET within strata defined by ethnicity and age

\begin{tabular}{lccc}
\hline & $65-74$ years & $75-84$ years & 85 years and older \\
\hline Non-Hispanic white & $5 / 249(2.0,0.3-3.7)$ & $10 / 229(4.4,1.7-6.9)$ & $3 / 111(2.7,0.0-5.7)$ \\
Non-Hispanic African-American & $5 / 270(1.9,0.2-3.4)$ & $17 / 271(6.3,3.3-9.1)$ & $16 / 101(15.8,8.0-22.0)$ \\
Hispanic & $12 / 336(3.6,1.5-5.5)$ & $27 / 298(9.1,5.8-12.3)$ & $12 / 68(17.6,8.1-25.9)$ \\
Other & $0 / 13(0.0)$ & $1 / 13(7.7,0-22.0)$ & $0 / 5(0.0)$ \\
\hline
\end{tabular}

Values are number of ET cases/number of participants. Percentages and 95\% CI are shown in parentheses). 
It is conceivable that handwriting tremor could have been the result of other medical comorbidities (especially, thyroid disease, stroke, arthritis) or tremor-producing medications. However, these comorbidities were no more common in our ET cases than in other participants. Similarly, the current use of a variety of tremor-producing medications (e.g., thyroid supplements, steroids, estrogen replacement therapy, insulin, oral hypoglycemic agents, antidepressants) did not differ in ET cases versus other participants. These data suggest that comorbidity and medications were not likely to have been the cause of tremor.

\section{Discussion}

The prevalence of ET was high (5.5\%) and rose markedly with age. In the oldest old, more than 1 in 5 individuals had ET. This study did not rely on a screening questionnaire, as was a design feature in several prior prevalence studies $[1,6,7]$. In a study in Italy, the crude prevalence of ET was $97 / 4,573$ (2.1\%) in persons aged $\geq 61$ years [6]. The low estimate was likely due to the fact that the initial examination was performed by general practitioners rather than neurologists specializing in movement disorders [6]. A study of Arabic villagers aged $\geq 65$ years in Israel also reported a low crude prevalence of $8 / 424$ (1.9\%), leading the investigators to query whether the prevalence might be particularly low in that ethnic group [7]. Dogu et al. [1] studied tremor in Mersin, Turkey. Each participant was examined by a study neurologist and the authors used the same standardized examination and diagnostic criteria as Inzelberg et al. [7], reporting a crude prevalence of ET (age $\geq 60$ years) of $39 / 622$ (6.3\%). Our results (prevalence in age $\geq 65$ years $=5.5 \%$ ) lie between those of previous studies $[1,6,7]$, yet closer to those of Dogu et al. [1].

Ethnic differences, if present in ET, could reflect differences in the prevalence of susceptibility genotypes; they could also reflect differences in exposure to environmental factors that have been associated with ET [20]. Ethnic differences in the prevalence of ET have received only modest attention. Tan et al. [12] studied the prevalence of ET in a community-based survey in Singapore, comparing Singaporean Chinese, Malays, and Indians. The prevalence was marginally higher in Indians than in Chinese $(p=0.08)$. No Malays with ET were identified. Inzelberg et al. [7] reported a very low prevalence among Arabic villagers in Israel; however, there was no formal comparison with other ethnic groups in Israel. In a study in Copiah county, Mississippi, there was a nonsignificant trend for ET to be higher among whites than AfricanAmericans although it is important to note that the study relied on an initial screening questionnaire, which could have biased results toward lower prevalence among less educated participants [11]. Similarly, an earlier study in northern Manhattan that analyzed data on 2,117 persons aged $\geq 65$ years recruited in 1992 (WHICAP I), reported a nonsignificant trend towards a higher prevalence in whites than African-Americans; however, that study also relied on an initial screening questionnaire [10]. By contrast, the current study, which did not rely on an initial screening questionnaire, reports a significant ethnic difference in the prevalence of ET, with the prevalence among whites being the lowest. Clearly, ethnic differences in ET require further study.

As reported previously $[1,5,21,22]$, the prevalence of ET increased with age. This is one feature of the disease that has been used to support the notion that it is degenerative. Recent postmortem studies report degenerativetype changes in the ET brain, including Purkinje cell loss [23-25]. Of additional interest is that prevalence of ET continued to rise in the oldest age groups. Prior studies of ET generally have not reported separate prevalence estimates for persons aged 90 and older. Other than our study, Mancini et al. [6] similarly reported that prevalence continued to rise in persons age 90 and older. There is a mixed literature in other late-life degenerative disorders (e.g. PD), with many demonstrating a continued increase with advancing age [26] while others suggest a reduction in incidence or prevalence in the oldest old [27, 28].

Approximately one-half of our ET cases did not report tremor. Previous work in community-based studies, in which ET cases often have mild tremor, has similarly demonstrated a high proportion of cases who do not report tremor (e.g., 28.3\% [10], 31.3\% [8], and 50.0\% [29]).

As noted above, in WHICAP I (1992), we estimated the prevalence of ET in an earlier, different sample of persons living in the same neighborhoods in northern Manhattan [10]. Aside from being a completely different sample from the one reported here, the earlier study used a different method for ascertaining ET cases (based on a screening questionnaire) and handwriting samples were not routinely analyzed as we did here. Hence, the earlier estimate of crude prevalence, 3.9\%, was lower than that reported here.

This study had limitations. First, ET was diagnosed based on handwriting. It is possible that we underascertained cases whose tremor manifested only during tasks 
other than writing. Thus, the results reported in this paper may be a conservative estimate of prevalence. In a previous population-based study of ET, we observed that $15.5 \%$ of ET cases had no tremor while drawing one spiral with their dominant arm [30]. Similarly, Dogu et al. [31] observed this value to be $12.4 \%$. However, in the current study, we used multiple different writing tasks/samples so that this proportion is likely to have been far lower. Even if the actual prevalence were $15 \%$ higher, it would have been similar to our estimate (6.3\% rather than $5.5 \%)$. On the other hand, we may also have included some cases of primary writing tremor [32]; however, this entity is rare [33] (by one estimate its prevalence was $1 / 200$ th that of ET) [34], and this would not have been a major source of misclassification. Second, we did not assess head tremor. However, previous ET series indicate that isolated head tremor cases comprise a small proportion of ET cases (e.g., $0.0 \%$ [35], $0.0 \%$ [7], 1.6\% [21], 2.0\% [34], 3.2\% [36]) so that this was not likely to have been a major source of underestimation. Third, we could not estimate prevalence in younger individuals. Fourth, family history data were not routinely collected so that we could not assess ethnic differences in familial tremor. Finally, although it is conceivable that we failed to ascertain tremor in individuals with severe ET who could not perform the writing tasks, our data indicate that no participants fell into this category.

This study had several strengths. First, it was population-based rather than clinic-based. Second, as in relatively few other studies $[1,6,7]$, our prevalence estimate was based on direct evaluation of each participant rather than a screening questionnaire. Such screens are known to have low sensitivities [21, 37]. Third, few prior studies have reported separate prevalence estimates for persons aged 90 and older [6]; we were able to address whether and to what extent the prevalence rose in the oldest old. Finally, with few other exceptions $[11,12]$, the Washington-Heights population is the only one in which ethnic differences in the prevalence of this common disorder have been directly assessed.

\section{Acknowledgements and Funding}

P01 AG07232 and R01 NS39422 from the National Institutes of Health (Bethesda, Md.).

\section{References}

1 Dogu O, Sevim S, Camdeviren H, Sasmaz T, Bugdayci R, Aral M, Kaleagasi H, Un S, Louis ED: Prevalence of essential tremor: Door-to-door neurologic exams in Mersin province, Turkey. Neurology 2003;61:18041806.

$\checkmark 2$ Benito-Leon J, Louis ED: Essential tremor: Emerging views of a common disorder. Nat Clin Pract Neurol 2006;2:666-678.

$\checkmark 3$ Moghal S, Rajput AH, Meleth R, D’Arcy C, Rajput R: Prevalence of movement disorders in institutionalized elderly. Neuroepidemiology 1995;14:297-300.

4 Moghal S, Rajput AH, D’Arcy C, Rajput R: Prevalence of movement disorders in elderly community residents. Neuroepidemiology 1994;13:175-178.

5 Louis ED, Ottman R, Hauser WA: How common is the most common adult movement disorder? Estimates of the prevalence of essential tremor throughout the world. Mov Disord 1998;13:5-10.

-6 Mancini ML, Stracci F, Tambasco N, Sarchielli P, Rossi A, Calabresi P: Prevalence of essential tremor in the territory of Lake Trasimeno, Italy: Results of a population-based study. Mov Disord 2007;22:540-545.
Inzelberg R, Mazarib A, Masarwa M, Abuful A, Strugatsky R, Friedland RF: Essential tremor prevalence is low in Arabic villages in Israel: door-to-door neurological examinations. J Neurol 2006;253:1557-1560.

8 Benito-Leon J, Bermejo-Pareja F, Louis ED: Incidence of essential tremor in three elderly populations of central Spain. Neurology 2005;64:1721-1725.

$\checkmark 9$ Rajput AH, Offord KP, Beard CM, Kurland LT: Essential tremor in Rochester, Minnesota: A 45-year study. J Neurol Neurosurg Psychiatry 1984;47:466-470.

10 Louis ED, Marder K, Cote L, Pullman S, Ford B, Wilder D, Tang MX, Lantigua R, Gurland B, Mayeux R: Differences in the prevalence of essential tremor among elderly African Americans, whites, and Hispanics in northern Manhattan, NY. Arch Neurol 1995;52: 1201-1205.

11 Haerer AF, Anderson DW, Schoenberg BS: Prevalence of essential tremor. Results from the Copiah county study. Arch Neurol 1982; 39:750-751.

12 Tan LC, Venketasubramanian N, Ramasamy V, Gao W, Saw SM: Prevalence of essential tremor in Singapore: A study on three races in an Asian country. Parkinsonism Relat Disord 2005;11:233-239.
13 Tang MX, Cross P, Andrews H, Jacobs DM, Small S, Bell K, Merchant C, Lantigua R, Costa R, Stern Y, Mayeux R: Incidence of Alzheimer's disease in African-Americans, Caribbean Hispanics and Caucasians in northern Manhattan. Neurology 2001;56: 49-56.

14 Louis ED, Schupf N, Manly J, Marder K, Tang MX, Mayeux R: Association between mild parkinsonian signs and mild cognitive impairment in a community. Neurology 2005;64:1157-1161.

15 Rosen W: The Rosen Drawing Test. Bronx, New York, Veterans Administration Medical Center, 1981.

16 Greenlief CL, Margolis RB, Erker GJ: Application of the trail making test in differentiating neuropsychological impairment of elderly persons. Percept Mot Skills 1985;61: 1283-1289.

17 Bain P, Findley LJ: Assessing Tremor Severity. London, Smith-Gordon, 1993.

$>18$ Louis ED, Zheng W, Jurewicz EC, Watner D, Chen J, Factor-Litvak P, Parides M: Elevation of blood-carboline alkaloids in essential tremor. Neurology 2002;59:1940-1944.

19 US Department of Commerce: 2000 census of population and housing. Profiles of general demographic characteristics, 2001. 
20 Louis ED: Environmental epidemiology of essential tremor. Neuroepidemiology 2008; 31:139-149.

-21 Benito-Leon J, Bermejo-Pareja F, Morales JM, Vega S, Molina JA: Prevalence of essential tremor in three elderly populations of central Spain. Mov Disord 2003;18:389394.

-22 Bergareche A, De La Puente E, Lopez De Munain A, Sarasqueta C, De Arce A, Poza JJ, Marti-Masso JF: Prevalence of essential tremor: A door-to-door survey in Bidasoa, Spain. Neuroepidemiology 2001;20:125128.

-23 Axelrad JE, Louis ED, Honig LS, Flores I, Ross GW, Pahwa R, Lyons KE, Faust PL, Vonsattel JP: Reduced Purkinje cell number in essential tremor: A postmortem study. Arch Neurol 2008;65:101-107.

-24 Shill HA, Adler CH, Sabbagh MN, Connor DJ, Caviness JN, Hentz JG, Beach TG: Pathologic findings in prospectively ascertained essential tremor subjects. Neurology 2008; 70:1452-1455.

$>25$ Louis ED, Faust PL, Vonsattel JP, Honig LS, Rajput A, Robinson CA, Pahwa R, Lyons KE, Ross GW, Borden S, Moskowitz CB, Lawton A, Hernandez N: Neuropathological changes in essential tremor: 33 cases compared with 21 controls. Brain 2007;130:3297-3307.
26 de Rijk MC, Tzourio C, Breteler MM, Dartigues JF, Amaducci L, Lopez-Pousa S, Manubens-Bertran JM, Alperovitch A, Rocca WA: Prevalence of parkinsonism and Parkinson's disease in Europe: The Europarkinson collaborative study. European community concerted action on the epidemiology of Parkinson's disease. J Neurol Neurosurg Psychiatry 1997;62:10-15.

27 Rajput AH, Offord KP, Beard CM, Kurland LT: Epidemiology of parkinsonism: Incidence, classification, and mortality. Ann Neurol 1984;16:278-282.

28 Morgante L, Rocca WA, Di Rosa AE, De Domenico P, Grigoletto F, Meneghini F, Reggio A, Savettieri G, Castiglione MG, Patti F, et al: Prevalence of Parkinson's disease and other types of parkinsonism: A door-to-door survey in three Sicilian municipalities. The Sicilian Neuro-Epidemiologic Study (SNES) Group. Neurology 1992;42:1901-1907.

29 Louis ED, Ford B, Wendt KJ, Ottman R: Validity of family history data on essential tremor. Mov Disord 1999;14:456-461.

30 Louis ED, Ford B, Wendt KJ, Lee H, Andrews $\mathrm{H}$ : A comparison of different bedside test for essential tremor. Mov Disord 1999;14: $462-467$.
31 Dogu O, Louis ED, Sevim S, Kaleagasi H, Aral M: Clinical characteristics of essential tremor in Mersin, Turkey - a populationbased door-to-door study. J Neurol 2005; 252:570-574.

-32 Klawans HL, Glantz R, Tanner CM, Goetz CG: Primary writing tremor: A selective action tremor. Neurology 1982;32:203-206.

>33 Singer C, Papapetropoulos S, Spielholz NI: Primary writing tremor: Report of a case successfully treated with botulinum toxin A injections and discussion of underlying mechanism. Mov Disord 2005;20:13871388.

34 Martinelli P, Gabellini AS, Gulli MR, Lugaresi E: Different clinical features of essential tremor: A 200-patient study. Acta Neurol Scand 1987;75:106-111.

35 Bain PG, Findley LJ, Thompson PD, Gresty MA, Rothwell JC, Harding AE, Marsden CD: A study of hereditary essential tremor. Brain 1994;117(pt 4):805-824.

36 Salemi G, Aridon P, Calagna G, Monte M, Savettieri G: Population-based case-control study of essential tremor. Ital J Neurol Sci 1998;19:301-305

37 Louis ED, Ford B, Pullman SL: Prevalence of asymptomatic tremor in relatives of patients with essential tremor. Arch Neurol 1997;54: 197-200. 